This is the author's final, peer-reviewed manuscript as accepted for publication. The publisher-formatted version may be available through the publisher's web site or your institution's library.

\title{
Factors influencing the implementation of organized physical activity and fruit and vegetable snacks in the HOP'N After- School Obesity Prevention Program
}

Tanis J. Hastmann, Melissa Bopp, Elizabeth A. Fallon, Richard R. Rosenkranz, David A. Dzewaltowski

\section{How to cite this manuscript}

If you make reference to this version of the manuscript, use the following information:

Hastmann, T. J., Bopp, M., Fallon, E. A., Rosenkranz, R. R., \& Dzewaltowski, D. A. (2013). Factors influencing the implementation of organized physical activity and fruit and vegetable snacks in the HOP'N After-School Obesity Prevention Program.

Retrieved from http://krex.ksu.edu

\section{Published Version Information}

Citation: Hastmann, T. J., Bopp, M., Fallon, E. A., Rosenkranz, R. R., \& Dzewaltowski, D. A. (2013). Factors influencing the implementation of organized physical activity and fruit and vegetable snacks in the HOP'N After-School Obesity Prevention Program. Journal of Nutrition Education and Behavior, 45(1), 60-68.

Copyright: (C) 2013 SOCIETY FOR NUTRITION EDUCATION AND BEHAVIOR

Digital Object Identifier (DOI): doi:10.1016/j.jneb.2012.06.005

Publisher's Link: http://www.sciencedirect.com/science/article/pii/S1499404612005039

This item was retrieved from the K-State Research Exchange (K-REx), the institutional repository of Kansas State University. K-REx is available at http://krex.ksu.edu 


\section{Factors Influencing the Implementation of Organized \\ Physical Activity and Fruit and Vegetable Snacks \\ in the HOP'N After-School Obesity Prevention Program}

Tanis J. Hastmann, $\mathrm{PhD}, \mathrm{MPH}^{1, \dagger}$; Melissa Bopp, $\mathrm{PhD}^{2}$; Elizabeth A. Fallon, $\mathrm{PhD}^{3}$; Richard R. Rosenkranz, $\mathrm{PhD}^{4}$; David A. Dzewaltowski, $\mathrm{PhD}^{5}$

${ }^{1}$ Department of Physical Education, Exercise Science, and Wellness, University of North Dakota, Grand Forks, ND

${ }^{2}$ Department of Kinesiology, Penn State University, University Park, PA

${ }^{3}$ Health Studies Program, The University of Rhode Island, Kingston, RI

${ }^{4}$ Department of Human Nutrition, Kansas State University, Manhattan, KS

${ }^{5}$ Department of Kinesiology, Kansas State University, Manhattan, KS

${ }^{\dagger}$ Dr. Tanis J. Hastmann was affiliated with the Department of Kinesiology, Kansas State University at the time this study was completed.

Address for correspondence: Tanis J. Hastmann, PhD, MPH, University of North Dakota, Department of Physical Education, Exercise Science, and Wellness, Grand Forks, ND 58202;

Phone: (701) 777-2994; Fax: (701) 777-3531; E-mail: tanis.hastmann@und.edu

http://dx.doi.org/10.1016/j.jneb.2012.06.005

Hastmann, T.J., Bopp, M., Fallon, E.A., Rosenkranz, R.R., \& Dzewaltowski, D.A. (2013) Factors influencing the implementation of organized physical activity and fruit and vegetable snacks in the HOP'N After-School Obesity Prevention Program. Journal of Nutrition Education and Behavior, 45(1):60-68. 


\section{INTRODUCTION}

Pediatric obesity has been shown to be associated with increased risk for chronic disease, such as, hyperlipidemia, dyslipidemia, metabolic syndrome, hypertension and type 2 diabetes mellitus. ${ }^{1}$ Children who participate in regular physical activity (PA) are less likely to be obese and may be more likely to participate in PA as adults. ${ }^{2}$ There is some evidence that increased consumption of fruits and vegetables (FV) decreases consumption of energy dense foods, total energy intake and adiposity. ${ }^{3-5}$

After-school time represents a key period in a child's weekday to deliver interventions to increase PA and FV intake. Compared to going home after school and being unsupervised, after-school programs provide adult supervision to decrease children's opportunities for obesity-related behaviors, such as screen time and sugar-sweetened beverage consumption and increase opportunities for healthful options. ${ }^{6-9}$ However, most adults supervising children in after-school programs do not engage children in physical activity and healthful eating. ${ }^{10}$

One major challenge to conducting obesity prevention research in after-school settings is to build the capacity of after-school staff to establish and maintain high-quality program implementation. ${ }^{7}$ Like school intervention studies ${ }^{11-13}$ the success of after-school obesity prevention programs is dependent on staff to implement PA and dietary interventions to children with high quality. However, many after-school leaders have little formal education or experience in the provision of free-play and organized PA, and a FV snack. ${ }^{15}$

This study sought to understand the factors that influenced the quality of implementation of the Healthy Opportunities for PA and Nutrition (HOP’N) after-school obesity prevention intervention. HOP'N was a three-year randomized controlled effectiveness trial designed to prevent obesity in fourth grade children attending after-school programs. ${ }^{15}$ Seven after-school programs were randomized to HOP'N $(n=4)$ or control $(n=3)$. The HOP'N intervention included three levels: community/government/human service agency 
(County Cooperative Extension), after-school staff training, and quality elements (organized daily PA for 30 min, daily FV snack, and weekly PA and FV education).

The purpose of the present study was to describe factors that influenced the quality of implementation of structured PA and a FV snack in HOP'N sites. Implementation of PA was defined as offering 30 minutes organized PA daily that engaged children in MVPA for at least $50 \%$ of active recreation time following CATCH PA principles. ${ }^{11}$ Implementation of a healthy snack was defined as providing a daily FV snack.

\section{METHODS}

\section{HOP’N INTERVENTION OVERVIEW}

The multilevel HOP'N intervention targeted the development of the skills and efficacy of adult leaders to build healthy after-school environments. The HOP'N intervention will be briefly described here and is described in detail elsewhere. ${ }^{15}$ The first level developed the capacity of a community/government/human service agency (County Cooperative Extension) to coordinate improving after-school programs. The research team provided technical assistance to the County Cooperative Extension office (Extension Assistant) to deliver an after-school training intervention and improve snack quality.

The second-level of the intervention included three after-school staff training sessions per year, and staff monthly meetings with the Extension Assistant. Trainings were modelled after the Healthy Places "performance community hub" where participants were encouraged to share and problem solve their implementation challenges, ${ }^{16,17}$ and received hands-one training on how to implement the HOP'N quality elements.

For the third level of intervention, after-school staff and the Extension Assistant implemented the HOP'N after-school quality elements at each intervention site. Staff had the goal to implement 30 minutes of daily, organized PA following CATCH Kids Club PA

principles. ${ }^{11}$ Specifically, CATCH games encourage children to be active all times, and the 
goal is participation and fun rather than winning. Each program received PA equipment and the CATCH Kids Club curriculum box. ${ }^{18}$ Also, to provide a daily FV snack, after-school program staff and the County Extension Office were directed to work with their school's food service staff. The research team did not provide snacks for the after-school programs. Finally, the Extension Assistant delivered a 60-minute, weekly HOP'N Club curriculum based on Social Cognitive Theory principles, ${ }^{15}$ at each HOP'N site.

Overall, the HOP'N after-school program did not impact changes in age- and genderadjusted body mass index. ${ }^{14}$ But, overweight/obese children attending HOP'N after-school programs performed approximately six minutes more MVPA per day after intervention. The HOP'N intervention was successful in building the capacity of staff to implement changes in the after-school program that led to positive PA changes. The HOP'N intervention was not successful in implementing changes in the number of FV offered as snacks. ${ }^{15}$

\section{PARTICIPANTS AND SETTING}

Interviews and surveys were conducted with staff from the HOP'N after-school sites $(\mathrm{n}=4)$ and included, organizational leaders $(\mathrm{OL})$, program managers $(\mathrm{PM})$, and group leaders (GL) (Year 1, n = 20; Year 2, n=17). A high turnover of after-school staff from year one to year two led to only few participants being interviewed both years. Data were collected at the end of each school year prior to staff leaving for summer vacation. OLs ( $n=3$ per year) were responsible for the overall implementation of the HOP'N project. They included the executive director of Boys \& Girls Club, executive director of planning and program improvement for the school district, and the school district food service director. The director of the Boys \& Girls Club was responsible for two of the after-school programs, and the director of the school district was responsible for the other two sites. PMs ( $n=4$ per year) were responsible for each after-school program. The PMs included the coordinator who supervised the after-school staff at each school site. GLs (year 1, $\mathrm{n}=13$; year 2, $\mathrm{n}=10$ ) were 
responsible for supervising groups of approximately 15 children. GLs were included if they were in charge of the fourth grade group, or if they led 30 minutes of organized CATCH PA at least once a week for the fourth grade group.

Participation was completely voluntary and interviews were kept confidential. This study was approved by the Institutional Review Board at Kansas State University and each participant provided informed consent.

\section{PROCEDURES}

A trained interview facilitator (lead author) conducted semi-structured interviews to understand factors influencing the daily implementation of 30 minutes organized PA and a healthy FV snack. The one-on-one interviews were conducted in private locations; were audio taped, and lasted 25-90 minutes.

The qualitative interview questions were based on a thorough review of the literature (i.e., school- and after-school health behaviour implementation research, process evaluation, physical activity and nutrition interventions), and on anecdotal evidence throughout the baseline year of the study. The interview guide went through several revisions by four experts in qualitative research. Interview questions were straightforward, open-ended, and were designed not to lead the interviewee. The interviews were organized into broad categories to assist the flow of the interview. Questions regarding the implementation of the HOP'N quality elements were organized around instances in which implementation was difficult or easy. Participants were asked to provide examples of occurrences when they did and did not implement PA and a healthy snack. Each question was developed with probes to ensure consistency between interviews. The moderator guide is provided in Tables 1 and 2 .

Following the semi-structured interview, each participant completed a brief survey including demographic information, MVPA participation, and FV consumption. GLs and PMs were asked additional questions regarding their self-efficacy ${ }^{18}$ to implement the HOP'N 
quality elements. The self-efficacy questions assessed how confident respondents were to (1) plan and (2) provide HOP'N CATCH 30 minutes of daily organized PA, and (3) follow the HOP'N CATCH daily routine. The HOP'N CATCH daily routine consisted of game rules not eliminating children, no standing in line, every child or every other child received a piece of equipment, and the goal was participation and fun rather than winning. Self-efficacy item scores were averaged for a scale score, and scale reliability $(\alpha=.67)$ was evaluated using Cronbach's alpha.

\section{DATA ANALYSIS}

The lead author and a trained research assistant transcribed interviews and the lead author checked all transcriptions for errors. The lead author maintained familiarity with the data and successfully identified general ideas and concepts throughout this process. To assist in organizing and managing the data, the transcribed data were imported to Qualitative Solutions and Research (QSR) NVivo version 2.0. The lead author developed themes for an initial coding guide based on the interview guide, knowledge (from transcribing the interviews), and was organized based on an ecologically informed social cognitive approach that informed the HOP'N after-school program. ${ }^{15-17}$ A social ecological approach ${ }^{20}$ allowed coders to illustrate staff (individual) and organizational influences on implementation. After the initial development of the coding guide, four experts reviewed it, and the guide went through several revisions. The lead author trained one independent coder. Following indepth discussions and initial practice sessions, both the researcher and independent coder coded five interviews separately for each year. Following the individual coding, the two coders compared codes and discussed minor discrepancies until consensus was reached. In a few instances, open codes were added to the coding guide during the coding process by both the lead author and independent coder. The open codes were necessary when the data did not conform to any codes in the coding guide. For example, a specific individual barrier to 
implementing daily organized PA was "providing children with enjoyable CATCH games". This code was not in the coding tree, but was added during the coding process. After this process, the researcher coded the remaining interviews and reviewed each interview with codes to check for completeness.

\section{RESULTS}

Participant demographic characteristics, PA habits, and FV consumption are reported in Table 3. To respect confidentiality, PM and OL characteristics were grouped together. PMs and GLs perceived they were successful in implementing 30 minutes of daily organized PA. However, participants described scenarios when the children did not receive 30 minutes daily organized PA. Facilitators and barriers influencing the implementation of organized PA were discussed. Although there were no objectively observed changes in FV offerings, ${ }^{15}$ the majority of participants perceived positive snack changes during the HOP'N intervention. Table 4 describes facilitators and barriers to improving the snack to include FV.

\section{DAILY ORGANIZED PA}

Most PMs and GLs believed they were successful in implementing 30 minutes daily organized PA. However, their definition of success was not consistent with the HOP'N evidence-based protocol of 30 minutes daily adult organized PA. Staff believed they were implementing the protocol as intended by increasing the amount of PA daily (organized or free play). Further questioning revealed situations where children did not receive daily organized PA in each of the after-school programs. Staff from each after-school program reported that they have "Free-day Fridays" and did not offer organized PA on these days. Similarly, one GL noted, “We don't get recreation (organized PA) on days when HOP'N Club is here. We still go outside, and they get their free play, but we don't do organized." 
Several themes emerged as facilitators to the implementation of organized PA, and after examining the data, were categorized into: organizational or staff facilitators. Examples within each of these categories are discussed.

Organizational facilitators included: training after-school staff; equipment, gym and outdoor space; scheduling organized PA; and restructuring the after-school program. Training after-school staff proved beneficial for the after-school staff that participated, for example, “I don't really like picking up a game that we don't really know and have them play it, so those games that we learn at HOP'N training we usually play those.”

Having a large gymnasium and plenty of outdoor space where organized PA could take place were frequently described facilitators. In addition, receiving the CATCH box and equipment at the start of the intervention facilitated HOP'N implementation. As mentioned by a PM, “I can't think of a single playground piece of equipment that we don't have... so that's cool because we don't have to play basketball or dodgeball every day." Scheduling organized PA by the PMs was necessary to implement organized PA. The PMs were responsible for providing daily and weekly schedules for the GLs to plan their time, and ensure that all children had access to the gym daily. As state by one of the PMs, "My program is small so I divide them up and the $4^{\text {th }}, 5^{\text {th }}$, and $6^{\text {th }}$ grade groups are together, it makes it easier to play the games.”

In year one, at one of the after-school programs, the PM restructured the after-school program to facilitate the implementation of organized PA by having a different GL implement different program offerings rather than one GL implement all program offerings. All the students received snack and 30 minutes of homework (as in previous years), then for the duration of after-school program (90 minutes) the children rotated between three stations with different GLs: enrichment, computers and organized PA. The GLs were divided into these three areas and were "champions" of each area. The CATCH station was implemented 
into the entire after-school program, and all grades played CATCH games. The PM expressed how having stations was helpful to implement organized PA daily, "Once they walk in (gym) they are walking the perimeter, they are getting ready to go. The two GLs (CATCH champions) still have to plan their week, but now they only have to focus on planning organized PA for all grades.”

Staff facilitators included: providing children with enjoyable games meeting $\mathrm{CATCH}$ guidelines; participating with children during organized PA; and high self-efficacy for implementing organized PA meeting $\mathrm{CATCH}$ guidelines. Providing children with enjoyable games meeting $\mathrm{CATCH}$ guidelines made implementing organized PA easier. GLs admitted to not looking through the CATCH Kids box for games; however in year two specifically, it was apparent that the games they described playing met the CATCH guidelines based on examples provided in the interviews. One GL described the games they played, "We're not good at following the actual CATCH games, but we're changing the games to keep them (the children) moving." Many GLs allowed the students to choose the games they played to limit the complaints as long as games met the CATCH guidelines, or GLs modified the games to meet CATCH guidelines.

Participating with children during organized PA was helpful to get children to participate. By having GLs participate in the games they were able to engage most children in higher activity levels, particularly the children who were typically less active or who did not like to play games. "If we just told them to play hospital tag, and we were on the sidelines talking they would just be walking and messing around, but if we play with them, it is just easier."

GLs and PMs indicated high self-efficacy for the overall implementation of PA. In year one, PMs' and GLs' self-efficacy was $94.2(\mathrm{SD}=11.7)$ and $77.5(\mathrm{SD}=24.8)$ on a 100\% scale, respectively, and in year two was $83.3(\mathrm{SD}=21.9)$ and $87.0(\mathrm{SD}=15.1)$. 
Several themes emerged as barriers to the implementation of 30 minutes daily organized PA. Similar to facilitators for implementation, two categories for barriers emerged: organizational and staff barriers.

Organizational barriers included: lack of school administration support, lack of PM support, high GL employee turnover, and low training attendance. Similar to school-based obesity prevention programs, after-school programs need the support of school administrators, principals, and teachers to ensure access to the gymnasium and other areas of the school building. In each year, school principals scheduled outside groups to use the gymnasium, leaving the after-school programs without an area to be physically active. For example, one participant stated "During the winter when it was really cold outside, our gym teacher had fitness camp for two weeks and we couldn't go in the gym at all, and we couldn't go outside because it was freezing."

Lack of PM support was a barrier to implementing organized PA. GLs required the support of their boss (PMs) to implement daily organized PA. However, the majority of GLs did not perceive that implementing organized PA was a requirement. In fact, one PM discussed not enforcing GLs to implement organized PA.

GLs had a high employee turnover rate, and typically only worked at the after-school programs for 6-12 months. Thus, each semester GLs had a tendency to change the age-group of children they were responsible for. Due to GLs changing the group they supervised, attendance at the HOP'N trainings was low as only the fourth-grade GLs were required to attend (attendance was only encouraged by other groups).

Staff barriers included: prioritizing PA, GL preference for free play PA, and providing children with enjoyable $\mathrm{CATCH}$ games. Academics and getting help with homework were higher priorities to most after school staff with PA being a lower priority. One GL reported, "They may miss recreation or enrichment if they have a lot of homework, but again, 
homework is the priority." Staff also reported that parents get upset when their children do not complete their homework during the after-school program.

In addition to academics and homework taking priority, many after-school staff believed that having a safe place and building positive, trusting relationships with the students was important. One GL noted, "Honestly, the most important aspect of the afterschool program doesn't have anything to do with academics, enrichment or recreation. It has to do with building relationships... to make the kids feel special, make them feel like they belong here, and make them feel like they are loved." Also, "It's important that kids have somewhere to go that's safe after-school, and that they're not involved with violence or drugs, or whatever... we provide a safe environment."

Most GLs reported that they preferred to let the children have recess or free play rather than organized PA. For example, "Of course we prefer recess, but where are the behavioural problems? They are during recess; we normally don't have any behavioural problems during recreation (organized PA) unless someone gets hurt. But, I'm still going to pick recess over recreation any day.”

GLs and PMs believed that the children did not enjoy the CATCH games and that made organized PA more difficult to implement. For example, one GL said, "We'll be playing a game that we found and the kids will hate it, so we ask them what they want to do, and all they want to do is kickball." In addition, the majority of after-school staff believed that children preferred free play to organized PA.

\section{DAILY HEALTHY SNACK}

Although objective observation indicated that there was no change in FV offerings, most staff perceived positive snack changes during the two year HOP'N program at their sites. "Snack has been much better now than it used to be, we're starting to get fresh FV more often, and we're not getting donuts and cookies." However, some OLs reported that 
the improvements were the result of the individual food service at each school, and not due to their efforts. The four-week snack menu was supposed to be the same at each site. However, our baseline data demonstrated that sites did not deliver the school district's menu as intended. ${ }^{17}$ Furthermore, interviews corroborated baseline data, indicating that there was wide variability in snack offerings between after-school programs. In both years, all participants reported that the goal of FV being offered at every snack was not met.

Several themes emerged as organizational barriers to the implementation of a daily FV snack. Barriers included: cost, lack of trust in after-school staff, and low priority of snack. According to the OLs, the biggest barrier to implementing a daily FV snack was the cost of additional staff to prepare, serve, and clean up the snack. The main priority of each school's food service staff was to serve lunch, and snack was merely an added task. There was not enough money in the budget to pay for someone to work two hours a day (10 hours per week) to prepare snack, which was necessary (according to the school food service director) to have a daily FV snack. Also, the school district is only minimally reimbursed for snack, making it difficult to provide FV for little cost.

Another large barrier to a daily FV snack was the lack of trust between OLs and school food service with PMs and GLs. Specifically, after-school staff did not receive food safety training, and were not trusted to be responsible with non-pre-packaged snacks.

The main focus of the school food service director was breakfast and lunch. Thus, each school's food service staff were not made accountable for following the snack menu, and were able to serve whatever they had an excess of or what was leftover from lunch.

Several PMs attempted to improve the quality of snack in the after-school programs and were somewhat successful. Staff strategies to improve snack quality included: requesting healthier snacks and expressing appreciation for the healthy snacks received. 
It was evident from the interviews that the relationship between the PM and school food service was the most important factor to improving the snack. A good relationship meant that when PMs requested certain foods to not be served and certain foods to be added, food service personnel would do their best to meet those requests. Also, if a relationship was built between food service and the after-school staff, it was easier to serve FV because they trusted that snack would be cleaned up and perishable food items would be put away.

Throughout the school year, each after-school program received FV sporadically. When PMs expressed their appreciation for the healthy snacks received, they were more likely to receive those snacks again.

\section{DISCUSSION}

The primary aim of this study was to identify factors that supported or impeded implementation of the HOP'N after-school obesity prevention program. Findings from this study suggest that the success of the after-school intervention, aimed at improving the afterschool organized PA and snack quality, is dependent on many factors, including several organizational system and staff variables. PMs and GLs negotiated these organizational and staff barriers and believed that they were successful in leading organized PA. However, their definition of success was not consistent with the evidence-based protocol that required organized PA five days a week for 30 minutes. After-school staff defined successful implementation as increasing the amount of organized and free-play PA daily. There were several organizational and staff facilitators that assisted in implementing PA, such as training; equipment, gym and outdoor space; and scheduling organized PA. However, key factors made implementing PA difficult, most notably, lack of school administration and PM support, not making organized PA a priority, high staff turnover and GL preference for free play PA. Implementing a daily FV snack proved most difficult as cost, lack trust of afterschool staff and making snack a priority were all barriers to successful implementation. 
Nevertheless, after-school staff perceived that they received more FV snacks, which was the result of requesting and expressing appreciation for the healthy snacks received from their schools food service staff. The after-school staff perceptions were not consistent with research staff observations, where programs did not receive more FV snacks. ${ }^{15}$

Consistent with other research, a continuous quality improvement model for training the after-school staff appeared to be an important facilitator for implementation. ${ }^{17,21,22}$ Afterschool staff typically lack formal training in healthy eating and PA, so providing a hands-on training was effective for successful implementation. Furthermore, it is likely that one-time trainings are not effective for several reasons. First, improving program implementation is a process of developing the capacity of staff to understand the principals behind the evidencebased protocol and to develop the capacity of staff to negotiate local barriers to implementation. Second, because there is a high turnover in staff, there needs to be continuous training to maintain institutional memory of intervention quality elements. Lastly, it may be beneficial to conduct part of the trainings with children present, to provide practice leading organized PA in a more "real-life" setting.

Scheduling by the PMs was a central issue in determining whether or not organized PA would be implemented. While PMs ensured that each group had access to the gym daily, most PMs did not make GLs accountable for implementing organized PA; thus it was often not viewed as a high priority by after-school staff. It may be that program priorities were determined by other funding (Department of Education $21^{\text {st }}$ Century Grants, United Way, user fees) or parent needs. Indeed, interest in after-school programs has been rapidly increasing due to their potential to boost a child's academic success. ${ }^{23}$ However, the $21^{\text {st }}$ Century grants are primarily focused on academic achievement, and not improving the quality or quantity of after-school PA or healthy food options. 
To improve the quality of snacks served in the after-school programs, individual factors were the most successful to overcome the organizational barriers. Similar to other studies, ${ }^{24}$ the largest barrier to providing a daily FV snack was cost; which included the actual purchase of $\mathrm{FV}$, and also the time to prepare and the potential for waste associated with fresh FV. The budget did not allow for additional staff to be hired to prepare an after-school snack, which meant GLs were the ones responsible to ensure snack was prepared. However, because of a lack of trust between OLs and after-school staff, GLs were not trusted to use school kitchens and therefore, the after-school staff were limited in what was served. To serve a snack that did not require much time to prepare, and resources in the kitchen, afterschool programs were primarily served pre-packaged, simple snacks. However, during the HOP'N after-school project, PMs and GLs learned that if they built a relationship with the food service personnel at their school and requested certain snacks to be taken off the menu or to be served, the food service personnel would attempt to meet those requests. This meant that after-school staff were able to influence the snacks served directly at their school, simply by being friendly and requesting certain snacks be served.

This study provides insight on the barriers and facilitators that affect implementation of organized PA and a healthy snack in an after-school program. The strengths include having the lead author conduct all, and transcribe most interviews. Second, four intervention after-school environments were explored, allowing for a wider range of events to be researched, thus increasing the implications for the research. Last, the organizational structure was in place prior to the HOP'N program intervention, and the intervention did not change the organizational structure of the after-school program, examining "real-life" programs.

Although this study offers insight into the implementation of organized PA and a healthy FV snack in after-school settings, a number of limitations exist. Generalizability is limited due to the selectivity of the sample and limited number of participants. Similarly, 
interviews were not conducted with food service staff at each school, which may have helped to understand barriers and facilitators to snack implementation. In addition, due to the small sample size, saturation may not have been reached. Last, all interviews were conducted at the end of year school year, thus, staff members leaving throughout the school year or at semester break were not included in this study.

Future research should examine whether interventions that target the organizational and staff variables identified by this study are more successful in program implementation. The HOP'N after-school project was successful at building the capacity of the staff to increase the amount of daily PA offered, but was unsuccessful at providing FV snack daily. Future research should focus on systemic changes in the after-school environment to increase the priority of daily organized PA and a healthy snack as mandatory components of afterschool programs.

\section{IMPLICATIONS FOR RESEARCH AND PRACTICE}

After-school programs provide a setting to reach children to provide an opportunity for organized PA and a healthy snack. ${ }^{6-8}$ However, there are several organizational and staff barriers that must be overcome. Thus, this study provides several recommendations for future after-school PA and nutrition programs.

First, state-wide childhood obesity prevention efforts need to offer continuous quality improvement training programs for OLs and after-school staff. One-time trainings are likely not to be effective. The HOP'N model provides multilevel intervention framework for obesity prevention that shows promise for wide spread dissemination. ${ }^{16,17}$

Second, governmental agencies and foundations that support after-school programs need to include implementation of daily PA and a healthy snack as a required quality element for funding. The American Dietetic Association, School Nutrition Association and Society for Nutrition Education developed a position that coordinated school health programs must 
include comprehensive, integrated nutrition services. ${ }^{25}$ After-school programs have the potential to positively impact school wellness policies and improve children's health via increased PA and FV consumption. However, Although OLs and PMs agreed to require daily organized PA; 30 minutes of homework and a snack were the only "mandatory" components of after-school programs perceived by staff in this study. It is likely that because continued funding was not tied to $\mathrm{PA}$ and $\mathrm{FV}$, these objectives were not a high priority. ${ }^{26,27}$

Third, after-school programs may need to develop PA specialists who are responsible for delivering activity to all the after-school age groups. In the first intervention year, one site developed stations where one GL's entire job was to implement organized PA. This GL position would act similarly as a physical education teacher in school, ensuring daily organized PA in the after-school program was delivered with high quality.

Finally, after-school programs need to offer PA daily, whether organized or free play, to increase caloric expenditure in children. Although the goal of this study was to understand factors that influenced the implementation of 30 minutes daily organized PA, the after-school programs response to this goal appeared to be to increase the amount of organized or free play PA they offered. ${ }^{15}$ These findings reflect the results of El Paso CATCH, which was an effectiveness trial to decrease overweight in children and encouraged schools to change the program to fit their specific needs, and thus much of the original program was not implemented as intended. ${ }^{28}$ It may be that given the challenges of promoting organized PA in after-school time, after-school staff adapted the intervention to meet these challenges.

Overall, findings from this study suggest the success of improving the after-school PA and FV snack quality is dependent on many factors, including several organizational system and staff variables. Future after-school obesity prevention interventions should consider the barriers and facilitators discussed to strengthen staff implementation.

\section{ACKNOWLEDGEMENTS}


This project was supported by a National Research Initiative Grant (no. 2005-3521515418) from the United States Department of Agriculture National Institute of Food and Agriculture to Kansas State University. We thank Karla Foster for her assistance with coding of the data. We also thank the Lawrence Kansas Public School District and Boys and Girls Club and their staff whose participation, time and energy made this study possible.

\section{REFERENCES}

1. Lee WWR. An overview of pediatric obesity. Pediatric Diabetes. 2007;8:76-87.

2. Nelson MC, Gordon-Larsen P, North KE, Adair LS. Body mass index gain, fast food, and physical activity: effects of shared environments over time. Obesity. 2006;14(4):701-709.

3. Bradlee ML, Singer MR, Qureshi MM, Moore LL. Food group intake and central obesity among children and adolescents in the Third National Health and Nutrition Examination Survey (NHANES III). Public Health Nutr. 2009;13(6):797-805.

4. Rolls BJ, Allo-Martin JA, Carlton Tohill B. What can intervention studies tell us about the relationship between fruit and vegetable consumption and weight management? Nutr Rev. 2004;62(1):1-17.

5. Wang Y, Ge K, Popkin BM. Why do some overweight children remain overweight, whereas others do not? Public Health Nutr. 2003;6:549-558.

6. Coleman KJ, Geller KS, Rosenkranz RR, Dzewaltowski DA. Physical activity and healthy eating in the after-school environment. J Sch Health. 2008;78(12):633-640.

7. Dzewaltowski DA. Community out-of-school physical activity promotion. In: Youth physical activity and sedentary behavior: Challenges and salutations. Edited by A.L. Smith, S.J.H. Biddle. Champaign, IL; Human Kinetics 2008, 377-401.

8. Koplan JP, Liverman CT, Kraak VI. Preventing childhood obesity: health in the balance: executive summary. J Am Diet Assoc. 2005;105(1):131-138.

9. Freedman MR, Nickell A. Impact of after-school nutrition workshops in a public 
library setting. J Nutr Educ Behav. 2010;42:192-196.

10. Miller WC, Hering M, Cothran C, Croteau K, Dunlap R. After-school physical activity and eating behaviors of middle school students in relation to adult supervision. $J$ Nutr Educ Behav. 2012; Feb 4.

11. Kelder SH, Mitchell PD, McKenzie TL, Derby C, Strikmiller PK, Luepker RV, Stone EJ. Long-term implementation of the CATCH physical education program. Health Educ Behav. 2003;30(4):463-475.

12. McKenzie TL, Sallis JF, Kolody B, Faucett FN. Long-term effects of a physical education curriculum and staff development program: SPARK. Res Q Exerc Sport, $1997 ; 68(4): 280-291$.

13. Ward DS, Saunders R, Felton GM, Williams E, Epping FN, Pate RR. Implementation of a school environment intervention to increase physical activity in high school girls. Health Educ Res, 2006;21(6):896-910.

14. US Department of Health and Human Services. Promoting physical activity and health nutrition in afterschool settings: Strategies for program leaders and policymakers. 2006. http://nccic.acf.hhs.gov/afterschool/fitness_nutrition.pdf. Accessed February 19, 2011. 15. Dzewaltowski DA, Rosenkranz RR, Geller KS, Coleman KJ, Welk GJ, Hastmann TJ, Milliken GA. HOP'N after-school project: an obesity prevention randomized controlled trial. IJBNPA. 2010;7(10).

16. Dzewaltowski DA, Estabrooks PA, Johnston JA. Healthy youth places promoting nutrition and physical activity. Health Educ Res. 2002;17(5):541-551.

17. Dzewaltowski DA, Estabrooks PA, Welk G, Hill J, Milliken G, Karteroliotis K, Johnston JA. Healthy youth places: A randomized controlled trial to determine the effectiveness of facilitating adult and youth leaders to promote physical activity and fruit and vegetable consumption in middle schools. Health Educ Behav. 2009;36(3):583-600. 
18. Kelder S, Hoelscher DM, Barroso CS, Walker JL, Cribb P, Hu S. The CATCH kids club: A pilot after-school study for improving elementary students' nutrition and physical activity. Health Nutr. 2005;8(2):133-140.

19. Bandura A. Self-efficacy: toward a unifying theory of behavioral change. Psychol Rev. 1977;84(2):191-215.

20. McLeroy KR, Bibeau D, Steckler A, Glanz K. An ecological perspective on health promotion programs. Health Educ Q. 1988;15:351-77.

21. Wiecha JL, Nelson TF, Roth BA, Glashagel J, Vaughan L. Disseminating health promotion practices in after-school programs through YMCA learning collaborative. Am J Health Promot. 2010;24(3):190-198.

22. Hirsch BJ, Mekinda MA, Stawicki JA. More than attendance: the importance of afterschool program quality. Am J Community Psychol. 2010:45:447-452.

23. INCRE, NIOST: Massachusetts After-School Research Study (MARS) Report. Arlington, MA; 2005

24. Cullen KW, Hartstein J, Reynold KD, et al. Improving the school food environment: results from a pilot study in middle schools. J Am Diet Assoc. 2007;107(3):484-489.

25. Briggs M, Fleischhacker S, Mueller CG. Position of the American Dietetic Association, School Nutrition Association, and Society for Nutrition Education: Comprehensive School Nutrition Services. J Nutr Educ Behav. 2010;42:360-371.

26. James-Burdumy S, Dynarski M, Deke J. After-school program effects on behaviour: results from the $21^{\text {st }}$ century community learning centers program national evaluation. Econ Inq. 2008;46(1):13-18.

27. National Center for Research in Education. Pathways to success for youth: what counts in after-school. 2005. http://www.niost.org/pdf/MARSReport.pdf. Accessed January 22, 2012. 
28. Coleman KJ, Tiller CL, Sanchez J, et al. Prevention of the epidemic increase in child risk of overweight in low-income schools: the El Paso coordinated approach to child health. Arch Pediatr Adolesc Med. 2005;159(3):217-224. 
Table 1: Moderators Guide: Overview of Major Topics and Questions

\begin{tabular}{|c|c|}
\hline Topic & Questions \\
\hline Background & $\begin{array}{l}\text { - Tell me a little about yourself and your role in the after-school program } \\
\text { - Tell me about a typical day at the after-school program } \\
\text { - In your opinion, what are the most important components of the after-school program? } \\
\text { Least important? Why? }\end{array}$ \\
\hline HOP'N Training & $\begin{array}{l}\text { - Generally speaking, what are your thoughts about the HOP'N training? } \\
\text { - How did or didn't the training prepare you to deliver the HOP'N program? } \\
\text { - What would you do to improve the training? }\end{array}$ \\
\hline General HOP'N Questions & $\begin{array}{l}\text { - What are your general impressions about HOP'N being at your school this past year(s)? } \\
\text { - How much time did you spend planning for HOP'N each week? } \\
\text { - Describe the effect HOP'N has had on your students, if any? } \\
\text { Since you've implemented HOP'N, what changes if any, have occurred at your school? }\end{array}$ \\
\hline Recreation/Free Play & $\begin{array}{l}\text { - Describe a typical recreation period. } \\
\text { - Compare and contrast the differences between free play and organized PA }\end{array}$ \\
\hline CATCH and organized PA & $\begin{array}{l}\text { - As you know, the goal of HOP'N is } 30 \text { minutes of CATCH organized PA, how } \\
\text { successful have you been at meeting that goal? } \\
\text { - How well do you feel you and the staff are implementing CATCH games? } \\
\text { - Please describe a few, organized/CATCH game sessions with the children } \\
\text { - What are the barriers to implementing } 30 \text { minutes of CATCH organized PA? } \\
\text { - What are the facilitators to implementing CATCH organized PA? } \\
\text { - What do you feel are the most important elements of CATCH? } \\
\text { - Do you have a preference for free play versus organized/CATCH? Why or why not? }\end{array}$ \\
\hline HOP'N Club & $\begin{array}{l}\text { - What do you like/dislike about HOP'N Club? } \\
\text { - Describe a typical HOP'N Club day compared to a "normal" day } \\
\text { - What are the differences between implementing HOP'N Club and implementing } \\
\text { CATCH PA and a FV snack, if any? }\end{array}$ \\
\hline Healthy FV Snack & $\begin{array}{l}\text { - Describe the changes, if any to the snack since HOP'N was implemented? } \\
\text { - What are the barriers to increasing the FV of the snack? } \\
\text { - What are the facilitators to increasing the FV of the snack? } \\
\text { - Describe the level of support food service employees have toward making healthy } \\
\text { changes to the snack? } \\
\text { - Describe your role, if any, to changing the snack? }\end{array}$ \\
\hline Perceptions of Supervision & $\begin{array}{l}\text { - Describe your professional relationship with your direct supervisor. How has the } \\
\text { support helped or not helped the implementation of the HOP'N program? }\end{array}$ \\
\hline Wrap Up & $\begin{array}{l}\text { - Since being a part of the HOP'N program, have you changed any of your own } \\
\text { behaviors? Examples. } \\
\text { - Can you discuss how sustainable you think the HOP'N program will be after this year } \\
\text { - To what extend do you feel your participation in HOP'N was "worth your time and } \\
\text { effort?" } \\
\text { - Is there anything else you would like to add or discuss? }\end{array}$ \\
\hline
\end{tabular}


Table 2: Additional questions for organizational leaders

\begin{tabular}{|c|c|}
\hline Topic & Questions \\
\hline $\begin{array}{l}\text { CATCH and organized } \\
\text { PA }\end{array}$ & $\begin{array}{l}\text { - Generally speaking, what are your thoughts about the CATCH games? } \\
\text { - What do you view as your role regarding physical activity in the after- } \\
\text { school programs? } \\
\text { - What are the barriers to getting the after-school programs to engage the } \\
\text { students in } 30 \text { minutes of organized, CATCH games daily? } \\
\text { - What are the facilitators to getting the after-school programs to engage } \\
\text { the students in } 30 \text { minutes of organized, CATCH games daily? }\end{array}$ \\
\hline Healthy FV Snack & $\begin{array}{l}\text { - Describe the changes, if any, to the snack since HOP'N was } \\
\text { implemented } \\
\text { - Whose responsibility is it to change the snacks? Why? } \\
\text { - Describe your role regarding changes to the snacks? } \\
\text { - During out observational trips to the after-school programs, we observed } \\
\text { that the same snack menu was not being followed in all the programs, } \\
\text { why do you think this is? Who is responsible for making sure the school } \\
\text { snack meets the requirements? }\end{array}$ \\
\hline Providing Support & $\begin{array}{l}\text { - Generally speaking, how do you support HOP'N being implemented in } \\
\text { the schools? } \\
\text { - What expectations do you have of your after-school staff? How are the } \\
\text { after-school staff members accountable for implementing the HOP'N } \\
\text { program, if at all? }\end{array}$ \\
\hline
\end{tabular}


Table 3: Interview Participant Demographic Information Years 1 and $2(n=37)$ 


\begin{tabular}{|c|c|c|c|c|}
\hline \multirow[b]{2}{*}{ Variables } & \multicolumn{2}{|c|}{ Year 1} & \multicolumn{2}{|c|}{ Year 2} \\
\hline & $\begin{array}{c}\text { Program Managers } \\
\text { \& Organizational } \\
\text { Leaders }\end{array}$ & $\begin{array}{l}\text { Group } \\
\text { Leaders }\end{array}$ & $\begin{array}{c}\text { Program Managers } \\
\text { \& Organizational } \\
\text { Leaders }\end{array}$ & $\begin{array}{c}\text { Group } \\
\text { Leaders }\end{array}$ \\
\hline $\mathbf{N}$ & 7 & 13 & 7 & 10 \\
\hline Gender: n (\%) & & & & \\
\hline Male & $2(29)$ & $4(30.8)$ & $1(14)$ & $3(30)$ \\
\hline Female & $5(71)$ & $9(69.2)$ & $6(86)$ & $7(70)$ \\
\hline Age: Mean (SD) & $37.3(\mathrm{SD}=14.3)$ & $21.3(\mathrm{SD}=1.1)$ & $\begin{array}{c}33.9(\mathrm{SD}=11.7) \\
23-51\end{array}$ & $21.8(\mathrm{SD}=1.3)$ \\
\hline Age: Range & $25-64$ & $19-23$ & & $20-24$ \\
\hline Ethnicity: n (\%) & & & & \\
\hline White & $6(86)$ & $10(76.9)$ & $7(100)$ & $8(80)$ \\
\hline Other & $1(14)$ & $3(23.1)$ & $0(0)$ & $2(20)$ \\
\hline Education: n (\%) & & & & \\
\hline In College & $2(29)$ & $12(92.3)$ & $1(14)$ & $8(80)$ \\
\hline Bachelor's & $2(29)$ & $1(7.6)$ & $3(43)$ & $2(20)$ \\
\hline Master's + & $3(43)$ & $0(0)$ & $3(43)$ & $0(0)$ \\
\hline BMI: & & & & \\
\hline n (\%) Normal Weight & $2(29)$ & $7(52.8)$ & $3(43)$ & $1(10)$ \\
\hline $\begin{array}{l}\text { n (\%) Overweight/Obese } \\
\text { n (\%) NA }\end{array}$ & $5(71)$ & $\begin{array}{l}5(38.5) \\
1(7.6)\end{array}$ & $4(57)$ & $9(90)$ \\
\hline n (\%) Meeting PA Guidelines & $4(57)$ & $11(84.6)$ & $4(57)$ & $8(80)$ \\
\hline $\begin{array}{l}\text { n (\%) Meeting Fruit } \\
\text { Consumption Guidelines }\end{array}$ & $6(86)$ & $6(46.2)$ & $3(43)$ & $6(60)$ \\
\hline $\begin{array}{l}\text { n (\%) Meeting Vegetable } \\
\text { Consumption Guidelines }\end{array}$ & $2(29)$ & $3(23.1)$ & $3(43)$ & $1(10)$ \\
\hline
\end{tabular}


Table 4: Barriers \& Facilitators for Healthy Snack Implementation: Major Themes and Illustrative Quotes

\begin{tabular}{l|l}
\hline Variable & Participant Quotations \\
\hline $\begin{array}{l}\text { Organizational Barriers } \\
\text { Cost }\end{array}$ & $\begin{array}{l}\text { "The problem is money. Because if you have cut-up fruits \& vegetables it } \\
\text { is a labor issue of cutting the apples or else buying prepared food that is in } \\
\text { little packages." (OL) } \\
\text { "I'm requested for healthier snacks, but when my equipment has been } \\
\text { abused, from having my pans ruined due to glitter (by after-school staff) } \\
\text { to having the lid to my milk cooler destroyed, trust is getting lost and it's } \\
\text { hard to gain back. So I go to a simple simple snack." (OL) } \\
\text { "Snack, as long as they get fed, because I go over budget on the snack... it } \\
\text { is just an expense to me." (OL) }\end{array}$ \\
$\begin{array}{l}\text { Snack not a priority } \\
\text { Requesting healthier snacks }\end{array}$ & $\begin{array}{l}\text { "We've requested no more donuts and the lunch lady doesn't supply } \\
\text { donuts anymore." (PM) } \\
\text { "She'll (food service staff) give us oranges, and I'll be like, 'the kids } \\
\text { really liked the oranges', and then for like a week and a half we'll get } \\
\text { oranges all the time." (PM) }\end{array}$ \\
\hline healthy snacks received
\end{tabular}

